\title{
Differences in glutathione S-transferase pi expression in transgenic mice with symptoms of neurodegeneration
}

\author{
Beata Kaźmierczak¹, Magdalena Kuźma-Kozakiewicz², Ewa Usarek and \\ Anna Barańczyk-Kuźma ${ }^{\circledR}$
}

${ }^{1}$ Chair and Department of Biochemistry, ${ }^{2}$ Chair and Department of Neurology, Medical University of Warsaw, Warszawa, Poland

Glutathione S-transferase pi (GST pi) is an enzyme involved in cell protection against toxic electrophiles and products of oxidative stress. GST pi expression was studied in transgenic mice hybrids (B6-C3H) with symptoms of neurodegeneration harboring SOD1G93A (SOD1/+), Dync1h1 (Cra1/+) and double (Cra1/SOD1) mutations, at presymptomatic and symptomatic stages (age 70, 140, 365 days) using RT-PCR and Western blotting. The main changes in GST pi expression were observed in mice with the SODG93A mutation. In SOD1/+ and Cra1/ SOD1 transgenics, with the exception of cerebellum, the changes in GST pi-mRNA accompanied those in GST pi protein. In brain cortex of both groups the expression was unchanged at the presymptomatic (age 70 days) but was lower at the symptomatic stage (age 140 days) and at both stages in hippocampus and spinal cord of SOD1/+ but not of Cra1/SOD1 mice compared to agematched wild-type controls. In cerebellum of the presymptomatic and the symptomatic SOD1/+ mice and presymptomatic Cra1/SOD1 mice, the GST pi-mRNA was drastically elevated but the protein level remained unchanged. In Cra1/+ transgenics there were no changes in GST pi expression in any CNS region both on the mRNA and on the protein level. It can be concluded that the SOD1G93A but not the Dync1h1 mutation significantly decreases detoxification efficiency of GST pi in CNS, however the Dync1h1 mutation reduces the effects caused by the SOD1G93A mutation. Despite similarities in neurological symptoms, the differences in GST pi expression between SOD1/+ and Cra1/+ transgenics indicate a distinct pathogenic entity of these two conditions.

Keywords: glutathione S-transferase pi, central nervous system, transgenic mice, SOD1G93A mutation, Dync1h1 mutation, motor neuron disease

Received: 29 July, 2011; revised: 07 October, 2011; accepted: 02 November, 2011; available on-line: 30 November, 2011

\section{INTRODUCTION}

Glutathione S-transferases (GSTs; EC 2.5.1.18) are a multigene family of isoenzymes classified as phase II detoxification enzymes. They catalyze the nucleophilic attack of the sulfur atom of glutathione (GSH) on the electrophilic groups of electrophilic substrates (Jakoby, 1978; Mannervik \& Danielson, 1988). Because of their low substrate specificity, GSTs play a critical role in protection of cells from injury by toxic chemicals including pesticides, carcinogens, drugs and products of oxidative stress (Hayes \& Pulford, 1995; Barańczyk-Kuźma et al., 2004; Tew, 1994). Based on biochemical properties, the cytosolic GSTs are divided into 8 subclasses named al- pha, kappa, mu, pi, sigma, theta, zeta, and omega (Mannervik et al., 1992). GST pi is most prevalent in mammalian cells, present at high level in many cancerous tissues and overexpressed in drug-resistant tumors (Ruzza et al., 2009; Inoue et al., 1995; Cookson et al., 1997; Laborde, 2010). It is expressed in the Central Nervous System, and has been the only subclass implicated in protection of cells from ROS-inducing agents (Awasthi et al., 1994; Beiswanger et al., 1995; Baez et al., 1997; Tew \& Ronai, 1999). Like other GSTs, the isoform pi is a carrier protein which non-enzymatically binds and transports a wide group of ligands within the cells, including hormones and neurotransmitters (Listowsky et al., 1988; Sawicki et al., 2000; Hayes \& Strange, 1995). Human brain GST pi can also bind antidepressants and seems to be responsible for the resistance of epileptic patients to antiepileptic drugs (Barańczyk-Kuźma et al., 2004; Shung et al., 2008).

Most GST classes show a high degree of polymorphism (Mo et al., 2009). GSTP polymorphisms affect substrate selectivity and increase the susceptibility to Parkinsonism-inducing effects of environmental toxins and late onset of Alzheimer's disease (AD) (Haves \& Strange, 2000; Bernardini et al., 2005). Reduced GST activity was found in multiple brain regions and ventricular cerebrospinal fluid in short postmortem interval in AD patients (Lovell, 1998). In our previous studies, we have observed significant decrease in GST pi expression in spinal cord, motor (but not sensory) brain cortex, as well as in peripheral blood mononuclear cells of patients with sporadic amyotrophic lateral sclerosis (Amyotrophic Lateral Sclerosis/Motor Neuron Disease, ALS/MND) (Usarek et al., 2005; Kuźma et al., 2006). ALS/MND is the most devastating condition among neurodegenerative diseases. It is characterized by progressive degeneration and loss of motor neurons, causing skeletal muscle wasting, paralysis and death (Rowland, 1995). In about 90\% of cases the origin of the disease is unknown (sporadic ALS). The toxicity of environmental factors, excitotoxicity, deprivation of neurotrophic factors, defects of RNA processing and oxidative stress, have been implicated in neuronal degeneration. However, factors underlying the neuronal loss remain unclear (Al-Chalabi et al., 1995; Terro et al., 1996; Kuźma-Kozakiewicz \& Kwieciński, 2011). In $5-10 \%$ of cases the disease is genetically determined (familiar ALS), and in one fifth of these cases

e-mail: anna.kuzma@wum.edu.pl

Abbreviations: GST pi, glutathione S-transferase pi; SOD1, superoxide dismutase 1; Dync1h1, dynein, cytoplasmic 1, heavy chain 1; Cra1, cramping 1; CNS, central nervous system; GSH, reduced glutathione; AD, Alzheimer's disease; ALS/MND, amyotrophic lateral sclerosis/motor neuron disease; MAPs, microtubule associated proteins; Loa, legs at odd angles; TDP-43, 43-kDa transactivating responsive sequence DNA-binding protein. 
it is linked to mutations in the SOD1 gene (Mulder et al., 1986). Transgenic mice that express human SOD1 gene with the G93A mutation develop ALS-like symptoms and are used as an animal model for ALS/MND studies (Dal Canto \& Gurney, 1995; Gurney et al., 1994; Tuy et al., 1996). However, the symptoms of neurodegeneration such as progressive locomotor disorders, early muscle weakness, hyperactivity were also observed in mice with missense point mutations in the heavy chains of cytoplasmic dynein (Dync1h1 gene), one of the microtubule associated proteins (MAPs) (Hafezparast et al., 2003). Due to abnormal body twisting and cramping of the hindlimbs, when suspended by tail, the mutations were called "Legs at odd angles" (Loa) and "Cramping 1" (Cra1). The phenotype of Cra1 mice is similar (but milder) to that of mice with the SOD1G93A mutation. The life span of Cra1 heterozygotes remains almost the same as that of wild-type animals, but in double heterozygotes (Loa/SOD1 and Cra1/SOD1) the disease progression is slower down and the life span increases slightly compared to SOD1G93A mice (Hafezparast et al., 2003; Kieran et al., 2005; Teuchert et al., 2006). Mice with mutations in the Dync1h1 gene were considered as a new, promising model of motor neuron degeneration (Hafezparast et al., 2003; Teuchert et al., 2006). Despite the fact that the Cra1 mice suffer from motor disturbances throughout their whole life, there are studies indicating that they display sensory neuropathy rather than motor neuron disease (Chen et al., 2007; Dupuis et al., 2009; Braunstein et al., 2010).

Due to the controversy about the involvement of Dync1h1 mutations in the pathogenesis of the motor neuron disease we studied GST pi expression in various parts of the central nervous system obtained from transgenic hybrid mice with human SOD1G93A mutation (SOD/+), with Dync1h1 mutation $(\mathrm{Cra1} /+)$ and with double Dync1h1/SOD1G93A mutations (Cra1/SOD1).

\section{MATERIALS AND METHODS}

Animals. The studies were conducted on mouse strain $\mathrm{C} 57 \mathrm{BL} / 6 \mathrm{GJ}-\mathrm{C} 3 \mathrm{H} / \mathrm{HeJ}(\mathrm{B} 6-\mathrm{C} 3 \mathrm{H})$ hybrids harboring human SOD1G93A amyotrophic lateral sclerosisassociated mutation (SOD1/+), dynein heavy chain 1 mutation (Dync1h1; so-called Cra1/+), double Dync1h1/ SOD1G93A mutation (Cra1/SOD1), and on genetic background-matched wild-type controls $(+/+)$. The SOD1G93A males (B6 background; Jackson Laboratories, Barr Harbor, ME, USA) were crossed with $\mathrm{Cra1} /+$ heterozygote female mice (C3He background; Ingenium Pharmaceuticals AG, Martinsried, Germany), as described earlier by Teuchert and coworkers (2006). There were 6 males in each studied group. Transgenic mice were at the presymptomatic stage (age 70 days for SOD $1 /+$ and Cra1/+SOD1, 70 and 140 days for $\mathrm{Cra} 1 /+$ ) and at the symptomatic stage (age 140 days for SOD $1 /+$, Cra1/SOD1, and 365 days for Cra1/+ mice). GST pi expression was determined in frontal cortex, hippocampus, spinal cord and cerebellum by RT-PCR and Western blotting.

Methods. Total RNA was isolated with the use of the NucleoSpin ${ }^{\circledR}$ RNAII kit (Macherey-Nagel) according to manufacturer's protocol followed by reverse transcription, polymerase chain reaction and DNA electrophoresis in agarose gel. Specific oligonucleotide primers for mice GST pi were as follows: 5'AGCCCACT'TGTCTG'TATGGG3' and 5'CAGGGCCT'TCACGTAGTCAT3'.
The GST pi-mRNA level was expressed as the ratio of the optical density of GST pi band to the optical density of $40 \mathrm{~S}$ ribosomal S12 protein RNA (housekeeping gene). Each assay was performed in duplicates and repeated 2 times.

Western blotting was performed after electrophoresis in 12\% SDS-polyacrylamide gel according to Laemmli (1970), with rabbit anti-GST-pi polyclonal antibodies (Novocastra). GST pi from human placenta was used as a standard (Sigma). Blots were visualized using ECL plus Western Blotting Detection System (Amersham). The assay was repeated 3-6 times for each tissue. Actin (monoclonal Anti-beta-Actin, Sigma) was used as a protein loading control. System UVI-KS4000, Syngen Biotechnology was used for densitometric analysis of RT-PCR and Western blotting. Results were expressed as means \pm S.D. and the data were analyzed by the two-way analysis of variance (ANOVA). Quantitative comparison between studied groups was performed by Student's t-test using Statistica 9.0 (StatSoft). Means were considered statistically significant at $p<0.05$.

The animal use was were approved by the Ethic Committee for Experiments on Animals at the Medical University of Warsaw, Poland (permission No. AOKEZ/622/3/2008).

\section{RESULTS}

\section{GST pi-mRNA expression}

GST pi-mRNA expression in frontal brain cortex of 70-day-old wild-type $(+/+)$ hybrid mice accounted for $0.97 \pm 0.2$ and was similar as in spinal cord $(0.89 \pm 0.09)$, but significantly $(p<0.0001)$ higher than in hippocampus and cerebellum $(0.68 \pm 0.04$ and $0.64 \pm 0.14$, respectively). In older mice, aged 140 and 365 days, the expression in brain cortex, hippocampus and spinal cord remained at the same level as in the younger group (aged 70 days). Only in cerebellum of 365 day-old mice it was almost 2 -fold higher than in younger groups $(1.15 \pm 0.06$, $p<0.0001$ ) (Fig. 1). In brain cortex of SOD $1 /+$ transgenics aged 70 days (presymptomatic stage) GST pi-mRNA expression did not differ from that in wildtype mice $(0.97 \pm 0.04)$, but in the 140 -day-old group (symptomatic stage) it was decreased to $0.68 \pm 0.15(30 \%$ decrease, $p<0.0001$ ) (Fig. 1). In hippocampus of each age group it was lower than in the age-matched control and accounted for $0.59 \pm 0.05(p<0.0001)$ and $0.56 \pm 0.06$ $(p<0.05)$ in 70 - and 140-day-old transgenics, respectively (Fig. 1). In spinal cord, GST pi-mRNA expression was significantly decreased in both age groups with $p<0.001$ for the younger and $p<0.05$ for the older one (Fig. 1). Differently than in other regions of $\mathrm{CNS}$, in cerebellum of SOD1/+ mice GST pi expression was significantly higher at both the presymptomatic and symptomatic stages reaching about $150 \%$ and $180 \%$ of the age-matched controls, respectively $(0.95 \pm 0.1$ in 70 -day-old mice and $1.18 \pm 0.15$ in 140 -day-old mice $(p<0.001)$ (Fig. 1). In Cra1/+ transgenics, GST pi-mRNA expression was unchanged in all investigated tissues at any studied age compared to the age-matched controls (Fig. 1). In Cra1/ SOD1 double hybrids, GST pi-mRNA expression was changed similarly as in the SOD1/+ groups but only in brain cortex of the symptomatic and cerebellum of the presymptomatic mice. In brain cortex of 140-day-old hybrids it accounted for $0.67 \pm 0.19(p<0.0001)$ and was about $30 \%$ lower than in the wild-type control, and in cerebellum it accounted for $0.91 \pm 0.05(p<0.0001)$ and 

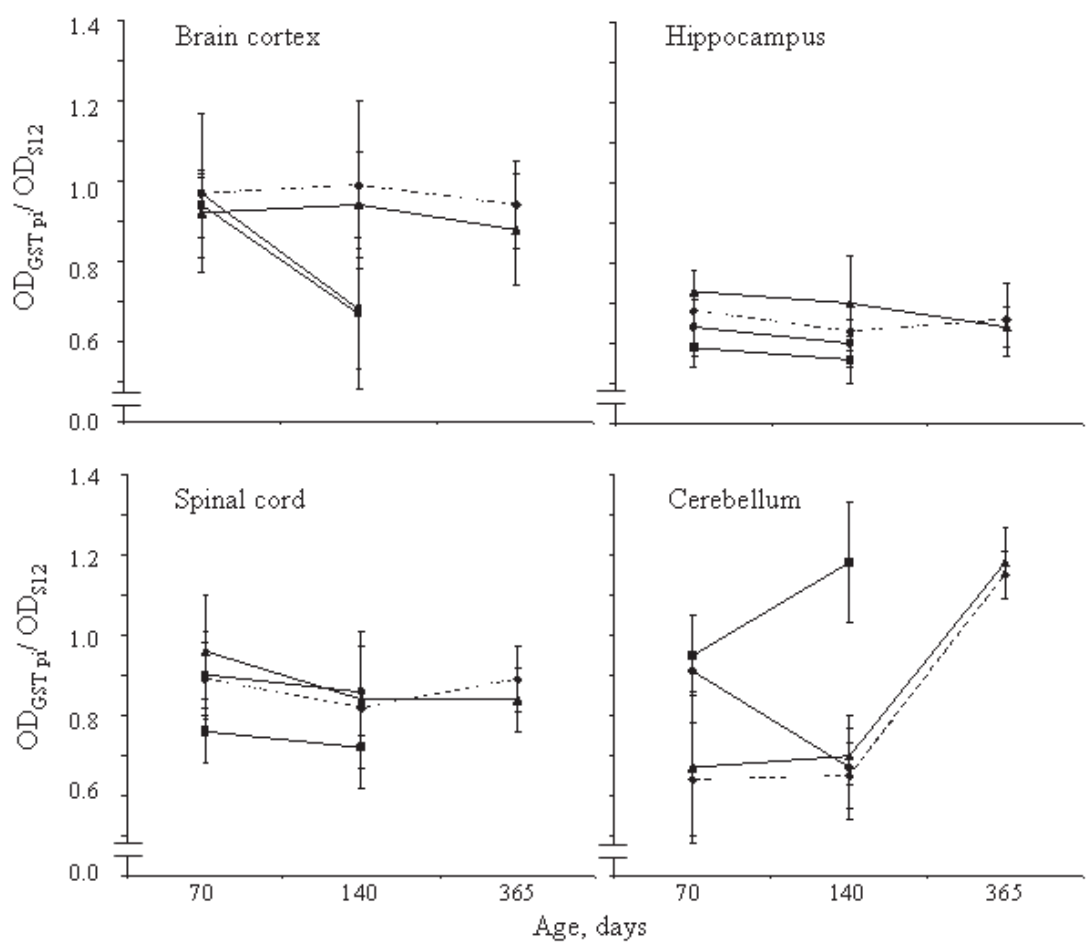

Figure 1. Age- and clinical stage-related GST pi-mRNA expression in CNS of transgenic mice.

GST pi-mRNA assessment was performed by RT-PCR and expressed as the ratio of optical density band of GST pi band to optical density of the $40 \mathrm{~S}$ ribosomal S12 protein RNA, as indicated in Materials and methods. $\bullet$, dashed lines, wild-type controls $(+/+)$; $\mathbf{a}$, SOD1/+ transgenics;, Cra1/SOD1 hybrides; $\boldsymbol{\Delta}$, Cra1/+ transgenics.

Table 1. Mean level of GST pi protein in various parts of CNS.

\begin{tabular}{|c|c|c|c|c|}
\hline \multirow{2}{*}{ Part of CNS } & \multicolumn{4}{|c|}{ GST pi protein in mice aged 70 days (ng/ $\mu \mathrm{g}$ of total protein) } \\
\hline & Wild-type $(+/+)$ & SOD1/+ & $\mathrm{Cra1/+}$ & Cra1/SOD1 \\
\hline Brain cortex & $10.0 \pm 3.7$ & $11.5 \pm 4.2$ & $10.1 \pm 2.2$ & $8.3 \pm 1.7$ \\
\hline Hippocampus & $6.6 \pm 0.9$ & $4.2 \pm 1.0$ & $6.1 \pm 1.2$ & $6.6 \pm 2.2$ \\
\hline Spinal cord & $12.7 \pm 4.9$ & $9.4 \pm 4.4$ & $11.1 \pm 3.3$ & $12.9 \pm 3.2$ \\
\hline Cerebellum & $8.6 \pm 2.7$ & $9.5 \pm 3.9$ & $8.8 \pm 2.6$ & $9.4 \pm 3.3$ \\
\hline \multirow{2}{*}{ Part of CNS } & \multicolumn{4}{|c|}{ GST pi protein in mice aged 140 days ( $\mathrm{ng} / \mathrm{\mu g}$ of total protein) } \\
\hline & Wild-type $(+/+)$ & SOD1/+ & Cra1/+ & Cra1/SOD1 \\
\hline Brain cortex & $10.5 \pm 4.0$ & $6.3 \pm 1.4$ & $10.0 \pm 3.8$ & $6.6 \pm 3.0$ \\
\hline Hippocampus & $6.3 \pm 1.0$ & $4.3 \pm 0.3$ & $6.1 \pm 0.8$ & $6.0 \pm 0.8$ \\
\hline Spinal cord & $10.2 \pm 3.2$ & $7.8 \pm 3.6$ & $10.5 \pm 3.4$ & $8.4 \pm 2.6$ \\
\hline Cerebellum & $\begin{array}{c}9.1 \pm 2.9 \\
13.3 \pm 1.5^{*}\end{array}$ & $\begin{array}{c}10.2 \pm 3.6 \\
-\end{array}$ & $\begin{array}{c}8.1 \pm 2.4 \\
13.2 \pm 2.0^{*}\end{array}$ & $\begin{array}{c}8.3 \pm 3.6 \\
-\end{array}$ \\
\hline
\end{tabular}

GST pi protein assessment was performed by Western blotting, as indicated in Materials and meth ods section. Each value is the mean \pm S.D. from 3-6 experiments.* values for mice age 365 days. was about $40 \%$ higher than in the age-matched control (Fig. 1). ANOVA analysis showed that GST pi-mRNA expression in brain cortex and cerebellum was dependent on the mutation and the age/clinical stage with F (4.12) $=5.96, \quad p=0.0002$ and $\mathrm{F}(4.80)=11.2, p=0.00001$, respectively. In hippocampus and spinal cord, statistical difference was only found between the GST pi-mRNA expression and the clinical stage $(\mathrm{F}=3.95, \quad p<0.05$ and $\mathrm{F}=11.02, \quad p<0.001$, respectively). The results also indicated that GST pi-mRNA expression was greatly related to the SOD1G93A but not Dync1h1 mutation. In mice with double mutation (Cra1/SOD1), the expression in brain cortex was more like in SOD1/+ mice but in hippocampus, spinal cord and cerebellum (symptomatic stage) it was like in $\mathrm{Cra1} /+$ mice.

\section{GST pi protein expression}

Mean values of GST pi protein expression are shown in Table 1 . In wild-type mice aged 70 and 140 days, the level of GST pi protein in brain cortex, spinal cord and cerebellum was similar (close to $10 \mathrm{ng} /$ $\mu \mathrm{g}$ of the total protein), but it was lower in hippocampus (about $6 \mathrm{ng} / \mu \mathrm{g}$ of the total protein) (Table 1). In cerebellum of older mice (age 365 days) it was almost 2-fold higher than in the younger groups and accounted for $13.50 \pm 1.54 \mathrm{ng} / \mu \mathrm{g}$ of the total protein (Table 1). In SOD $1 /+$ and Cra1/SOD 1 transgenic mice, with the exception of cerebellum, the profile of GST pi protein accompanied that of GST pi-mRNA. In brain cortex of both groups it was unchanged at the presymptomatic (age 70 days) but was lower at the symptomatic stage (age 140 days) (Fig. 2A, B), and in hippocampus and spinal cord of SOD1/+ but not Cra1/ SOD1 mice, at both stages when compared to age-matched wild-type controls (Table 1). In cerebellum of 70 - and 140-dayold SOD $1 /+$ and Cra1/SOD 1 mice, GST pi protein was at the same level as in the control groups (Table 1, Fig. 2C, D). In Cra1/+ transgenics the expres- 
sion was unchanged in all studied tissues, and in all agegroups (Table 1, Fig. 2).

\section{DISCUSSION}

Till now, the exact mechanisms underlying sporadic ALS/MND are not known, but also it is not clear how mutations in the SOD1 gene contribute to pathogenesis of the disease (Kuźma-Kozakiewicz \& Kwieciński, 2011). In our previous studies we have observed a significant decrease in glutathione S-transferase activity in peripheral blood mononuclear cells of patients with sporadic ALS (Kuźma et al., 2006). The decrease in activity was accompanied by the decrease in GST pi expression at both mRNA and protein levels. Since we also observed a decrease in GST pi expression in spinal cord and motor cortex of ALS cases, we concluded that the protective barrier formed by this enzyme was originally affected in sporadic ALS/MND. Thus, the subjects would be more sensitive to the toxicity of electrophilic compounds and organic peroxides (Usarek et al., 2005; Kuźma et al., 2006). In the present studies we observed similar changes in GST pi expression in brain cortex and spinal cord (about 30 and $15 \%$ decrease, respectively) obtained from mice harboring human SOD1G93A mutation (animal model for familial ALS). The decrease that we observed in SOD1/+ mice appeared in brain cortex at the symptomatic stage - age 140 days (not at the presymptomatic - age 70 days) and was more pronounced than in spinal cord, where it appeared earlier (prior to symptoms) but was independent of age and clinical stage. When we expanded our studies over the regions of CNS believed not to be affected in ALS/MND, we found a slight decrease in GST pi expression in hippocampus (on both mRNA and protein levels), and a high increase in GST
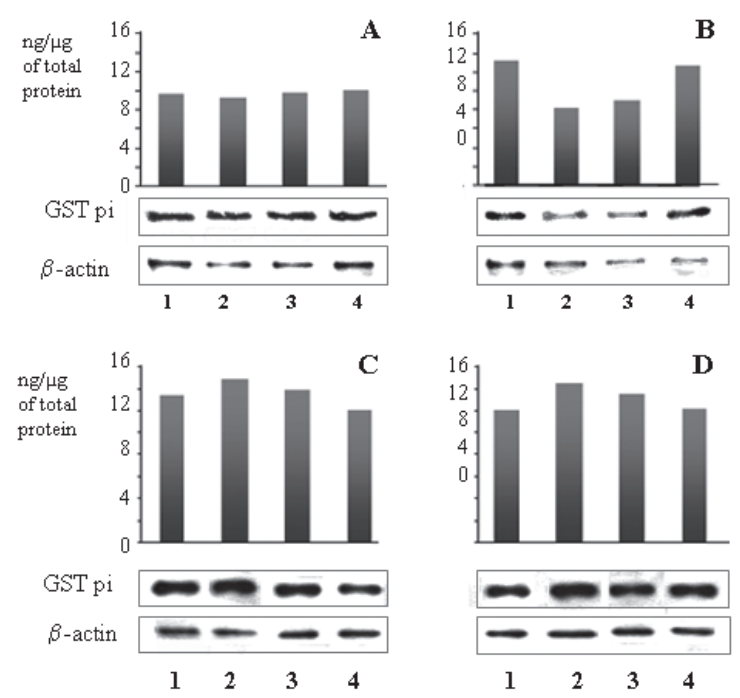

Figure 2. GST pi protein level in brain cortex and cerebellum. Protein was determined by Western blotting, as indicated in Materials and methods. Comparable amounts of protein $(6 \mu \mathrm{g})$ were run in each lane. A and B, GST pi in brain cortex of mice aged 70 and 140 days, respectively; C and D, GST pi in cerebellum of mice aged 70 and 140 days, respectively. GST pi (100ng) from human placenta was used as a standard and $\beta$-actin as a protein loading control. A: Lane 1, wild-type (OD 212), lane 2, SOD1/+ (OD 191), lane 3, Cra1/SOD1 (OD 238), lane 4, Cra1/+ (OD 246); B: Lane 1, wild-type (OD 257), lane 2, SOD1/+ (OD 117), lane 3, Cra1/SOD1 (OD 129), lane 4, Cra1/+ (OD 244); C: Lane 1, wild-type (OD 252), lane 2, SOD1/+ (OD 279), lane 3, Cra1/SOD1 (OD 261), lane 4, Cra1/+ (OD 227); D: Lane 1, wild-type (OD 220), lane 2, SOD1/+ (OD 226), lane 3, Cra1/SOD1 (OD 249), lane 4, Cra1/+ (OD 224).
pi-mRNA in cerebellum. GST pi-mRNA expression in cerebellum escalated with age/stage reaching about 150 and $180 \%$ compared to the age-matched controls. However, the changes in GST pi-mRNA expression were not accompanied by the changes in GST pi protein. Recently, studying tau expression in cerebellum of hybrid mice with human SODG93A mutation at presymptomatic and symptomatic stages, we observed a dramatic increase in the level of total tau-mRNA, in tau $0 \mathrm{~N}, 1 \mathrm{~N}, 2 \mathrm{~N}$ isoformmRNA but not in the tau protein (Kuźma-Kozakiewicz et al., 2011). Cerebellum is the structure usually not studied in motor neuron diseases, since cerebellar dysfunction is not a clinical feature of ALS. However, it is possible that gait disturbance observed at early stages of ALS, and usually explained by the instability of paretic muscles, may result from the primary involvement of cerebellum. Moreover, there are studies that indicate the disturbances in the expression of various proteins in this structure. The pathological $43-\mathrm{kDa}$ transactivating responsive sequence DNA-binding protein (TDP-43) was identified as the major disease protein in many areas of the central nervous systems of ALS patients, including cerebellum (Geser et al., 2008). Chung and coworkers (2005, 2008) detected the presence of astrocytes immunoreactive to phosphorylated extracellular signal-regulated kinases and glycogen synthase kinase 3alpha involved in anti-apoptotic signal transduction pathways in spinal cord, brainstem, central gray and cerebellar nuclei of symptomatic SODG93A mice. Therefore, more studies are needed to explain why the increase in GST pi-mRNA is not accompanied by an increase in protein.

Intracellular transport along microtubules is especially important in motor neurons, the axons of which may reach the length of over one meter (El-Kadi et al., 2007). The defects in the retrograde axonal transport appear in motor neurons of SOD1G93A mice very early in the embryonic development (Kieran et al., 2005). An impaired retrograde axonal transport was also observed in genetic defects of the dynein complex, one of the microtubule associated proteins (MAPs) (Gibbons, 2005; Goldstein \& Yang, 2000). The cytoplasmic dynein complex is formed by two identical heavy chains, a few intermediate, and several light chains (Samso et al., 1988). Heavy chains are encoded by a 78-exon gene, Dync1h1. They bind ATP, a source of energy for dynein movement along microtubules. Knocking out Dync1h1 results in early embryonic lethality in mice (Harada et al., 1998). Mice with autosomal dominant missense point mutations in the Dync1h1 gene show a progressive limb paresis. In Cra1 mice, the mutation (Cra1: 1051VWLQCQCLW1059; wild type: 1051VWLQYQCLW1059) within dynein heavy chains leads to the exchange of tyrosine by cysteine and subsequently to an age-related progressive degeneration of the motor neurons. On the molecular level Cra1 mice show defects in the dynein complex resulting in an impaired retrograde axonal transport (Hafezparast et al., 2003; Hrabe de Angelis et al., 2000; LaMonte et al., 2002). However, crossing SOD1G93A mice with Loa or Cra1 delays the disease progression and significantly increases the life span of SOD1 double heterozygotes (Loa/SOD1 and Cra1/SOD1) (Kieran et al., 2005). Thus, mutations in the Dync1h1 gene appear to influence the progression of motor neuron degeneration and SOD1G93A-toxicity (Kieran et al., 2005; Teuchert et al., 2006). In our studies no changes in GST pi expression were observed either on the mRNA or on protein level in any studied part of CNS in Cra1/+ mice. In Cra1/SOD1 groups, GST pi expression was changed only in brain cortex, where 
it was decreased identically as in the SOD $1 /+$ symptomatic group.

Our results indicated that the protective barrier formed by GST pi is affected in CNS of mice with the SOD1G93A but not with the Dync1h1 mutation. This may expose the brain and spinal cord to the toxicity of uncompletely inactivated toxic compounds including organic peroxides, and subsequently contribute to neurodegeneration. Despite similarities in neurological symptoms, the differences in GST pi expression between SOD1/+ and $\mathrm{Cra1} /+$ transgenics indicate a distinct pathogenic entity of these two conditions. However, a mutation in the Dync1h1 gene that impairs the physiological function of the dynein complex, seems to be beneficial for GST pi expression in SOD1-related ALS/MND. This is the first report concerning GST pi expression in various CNS regions of mice with the G93A mutation in human SOD1, mice with a mutation in the heavy chain of cytoplasmic dynein (Dync1h1 gene), and mice with the double SOD1G93A/Dync1h1 mutations. More studies are needed to explain the molecular mechanism of these findings.

\section{Acknowledgements}

This study was supported by grants N N401 031337 from the Ministry of Science and Higher Education of Poland and 1WK/WB2/09 from the Medical University of Warsaw, Poland.

The Authors would like to thank Prof. Albert C. Ludolph and Dr. Birgit Schwalenstöcker from the University of Ulm, Germany for providing tissues from transgenic mice.

\section{REFERENCES}

Al-Chalabi A, Powell JF, Leigh PN (1995) Neurofilaments, free radicals, excitotoxins, and amyotrophic lateral sclerosis. Muscle Nerve 18: 540-545.

Awasthi YC, Sharma R, Singhal SS (1994) Human glutathione S-transferases. Intern I Biochem 26: 295-308.

Baez S, Segura-Aguilar J, Widersten M, Johansson AS, Mannervik B (1997) Glutathione transferases catalyse the detoxication of oxidized metabolites (o-quinones) of catecholamines and may serve as an antioxidant system preventing degenerative cellular processes. Biochem J 324: 25-28.

Barańczyk-Kuźma A, Kuźma M, Gutowicz G, Kaźmierczak B, Sawicki J (2004) Glutathione S-transferase pi as a target for tricyclic antidepressants in human brain. Acta Biochim Pol 5: 207-212.

Beiswanger CM, Diegmann MH, Novak RF, Philbert MA, Grassle TL, Reuhl KR, Lowndes HE (1995) Developmental changes in the cellular distribution of glutathione and glutathione S-transferases in the murine nervous system. Neurotoxicology 16: 425-440.

Bernardini S, Bellincampi L, Ballerini S, Federici G, Iori R, Trequattrini A, Ciappi F, Baldinetti F, Bossu P, Caltagirone C (2005) Glutathione $S$-transferase P1 $* C$ allelic variant increases susceptibility for late-onset Alzheimer disease: association study and relationship with apolipoprotein 4 allele. Clin Chem 51: 944-951.

Braunstein KE, Eschbach J, Rona-Voros K, Soylu R, Mikrouli E, Larmet Y, Rene F, De Aguilar JL, Loeffler JP, Muller HP, Bucher S, Kaulisch T,. Niessen HG, Tillmanns J, Fischer K, Schwalenstocker B, Kassubek J, Pinchler B, Stiller D, Petersen A, Ludolph AC, Dupuis L (2010) A point mutation in the dynein heavy chain gene leads to striatal atrophy and compromises neurite outgrowht of structal neurons. Hum Mol Genet 19: 4385-4398.

Cookson MS, Reuter VE, Linkov I, Fair WR (1997) Glutathione Stransferase PI (GST-pi) class expression by immunohistochemistry in benign and malignant prostate tissue. J Urol 157: 673-676.

Chen X-J, Levedakou EN, Millen KJ, Wollmann RL, Soliven B, Popko B (2007) Proprioceptive sensory neuropathy in mice with a mutation in the cytoplasmic dynein heavy chain 1 gene. J Neurosci 27: 14515-1524.

Chung YH, Joo KM, Lim HC, Cho MH, Kim D, Lee WB, Cha CI (2005) Immunohistochemical study on the distribution of phosphorylated extracellular signal-regulated kinase (ERK) in the central nervous system of SOD1G93A transgenic mice. Brain Res 19: 203-209.
Chung YH, Joo KM, Kim D, Kim SS, Kim KY, Lee WB, Cha CI (2008) Immunohistochemical study on the distribution of glycogen synthase kinase 3alpha in the central nervous system of SOD1(G93A) transgenic mice. Neurol Res 30: 926-931.

Dal Canto MC, Gurney ME (1995) Neuropathological changes in two lines of mice carrying a transgene for mutant human CuZn SOD and in mice overexpressing wild type human SOD: a model of familial amyotrophic lateral sclerosis. Brain Res 676: 25-40.

Dupuis L, Fergani A, Braunstein KE, Eschbach J, Holl N, Rene N, Gonzalez De Aguilar JL, Zoerner B, Schwalenstocker B, Ludolph AC, Loeffler JP (2009) Mice with a mutation in the dynein heavy chain 1 gene display sensory neuropathy but lack motor neuron disease. Exp Neurol 215: 146-152.

El-Kadi AM, Soura V, Hafezparast M (2007) Defective axonal transport in motor neurodisease. J Neuros Res 85: 2557-2566.

Geser F, Brandmeir NJ, Kwong LK, Martinez-Lage M, Elman L, McCluskey L, Xie SX, Lee VM, Trojanowski JQ (2008) Evidence of multisystem disorder in whole-brain map of pathological TDP_43 in amyotrophic lateral sclerosis. Arch Neurol 65: 636-641.

Gibbons IR (1995) Dynein family of motor proteins: present status and future questions. Cell Motil Cytoskeleton 32: 136-144.

Goldstein LS, Yang Z (2000) Microtubule-based transport systems in neurons: the roles of kinesins and dyneins. Annual Rev Neurosci 23: 39-71.

Gurney ME, Pu H, Chiu AY, Dal Canto MC, Polchow CY, Caliendo J, Aleksander DD, Hentati A, Kwon YW, Deng HX, Chen W, Zhai P, Sufit RL, Siddique T (1994) Motor neuron degeneration in mice that express a human $\mathrm{Cu}, \mathrm{Zn}$ superoxide dismutase mutation. Science 264: 1772-1775.

Hafezparast M, Klocke R, Ruhrberg C, Marquardt A, Ahmad-Annuar A , Bowen S, Lalli G, Witherden AS, Hummerich H, Nicholson S, Morgan PJ, Oozageer R, Priestley JV, Averill S, King RV, Ball S, Peters J, Toda T, Yamamoto A, Hiraoka Y, Augustin M, Korthaus D, Wattler S, Wabnitz P, Dickneite C, Lampel S, Boehme G, Peraus G, Popp A, Rudelius M, Schlegel J, Fuchs H, Hrabe de Angelis M, Schiavo DT, Shima G, Russ AP, Stumm G, Martin JE, Fisher EM (2003) Mutations in dynein link motor neuron degeneration to defects in retrograde transport. Science 300: 808-881.

Harada H, Takei Y, Kanai Y, Tanaka Y, Nonaka S, Hirokawa N (1998) Golgi vesiculation and lysosome dispersion in cells lacking cytoplasmic dynein. J Cell Biol 141: 51-59.

Hayes JD, Pulford DJ (1995) The glutathione S-transferase supergene family: regulation of GST and the contribution of the isoenzymes to cancer chemoprotection and drug resistance. Crit Rev Biochem Mol Biol 3: 445-600.

Hayes JD, Strange RC (1995) Potential contribution of the glutathione S-transferase supergene family to resistance to oxidative stress. Free Radic Res 22: 193-207.

Hayes JA, Strange RC (2000) Glutathione S-transferase polymorphisms and their biological consequences. Pharmacology 61: 154-166.

Hrabe de Angelis MH, Flaswinkel H, Fuchs H, Rathkolb B, Soewarto D, Marschall S, Heffner S, Pargent W, Wuensch, K Jung M, Reis A, Richter T, Alessandrini F, Jakob T, Fuchs E, Kolb H, Kremmer E, Schaeble K, Rollinski B, Roscher A, Peters C, Meitinger T, Strom T, Steckler T, Holsboer F, Klopstock T, Gekeler F, Schindewolf C, Jung TM, Avraham K, Behrendt H, Ring J, Zimmer A, Schughart K, Pfeffer K, Wolf E, Balling R (2000) Genome-wide, large-scale production of mutant mice by ENU mutagenesis. Nat Genet 25: $444-447$.

Inoue T, Ishida T, Sugio K, Maehara Y, Sugimachi K (1995) Glutathione S-transferase $\mathrm{Pi}$ is a powerful indicator in chemotherapy of human lung squamous-cell carcinoma. Respiration 62: 223-227.

Jakoby WB (1978) The glutathione S-transferases: a group of multifunctional detoxication protein. Adv Enzymol 46: 383-414.

Kieran D, Hafezparast M, Bohnert S, Dick JR, Martin J, Schiaro G (2005) A mutation in dynein rescues axonal transport defect and extends the life span of ALS mice. J Cell Biol 169: 561-567.

Kuźma M, Jamrozik Z, Barańczyk-Kuźma (2006) A Activity and expression of glutathione S-transferase pi in patients with amyotrophic lateral sclerosis. Clin Chim Acta 364: 217-221.

Kuźma-Kozakiewicz M, Kwieciński H (2011) New therapeutic targets for amyotrophic lateral sclerosis. Expert Opin Ther Targets 15: 127143.

Kuźma-Kozakiewicz M, Usarek E, Barańczyk-Kuźma A (2011) Mice with mutation in dynein heavy chain 1 do not share the same tau expression pattern with mice with SOD1-related motor neuron disease. Neurochem Res 36: 978-985.

Laborde E (2010) Glutathione transferases as mediators of signaling pathways involved in cell proliferation and cell death. Cell Death Differentiation 17: 1373-13180.

LaMonte BH, Wallace KE,. Holloway BA, Shelly SS, Ascaño J, Tokito M, Van Winkle T, Howland DS, Holzbaur EL (2002) Disruption of dynein/dynactin inhibits axonal transport in motor neurons causing late-onset progressive degeneration. Neuron 34: 715-727.

Laemmli UK (1970) Cleavage of structural proteins during the assembly of the head of bacteriophage T4. Nature 227: 680-685. 
Listowsky L, Abramowitz M, Homma H, Nitsu Y (1988) Intracellular binding of hormones and xenobiotics by glutathione S-transferases. Drug Met Rev 19: 305-318. Lovell MA, Xie C, Markesbery WR (1998) Decreased glutathione transferase activity in brain and ventricular fluid in Alzheimer's disease. Neurology 51: 1562-1566.

Mannervik B, Awasthi YC, Board PG, Hayes JD, Di Ilio C, Ketterer B, Listowsy R, Morgenstern R, Muramatsu M, Pearson WR, Pickett CB, Sato K, Wildersten M, Wolf CR, (1992) Nomenclature for human glutathione transferases. Biochem J 282: 305-306.

.Mannervik B, Danielson UH (1988) Glutathione transferases - structure and catalytic activity. CRC. Crit Rev Biochem 23: 283-337.

Mo Z, Gao Y, Cao Y, Gao F, Jian L (2009) An updating meta-analysis of the GSTM1, GSTT1, and GSTP1 polymorphism and prostate cancer: a HuGE review. Prostate 69: 662-668.

Mulder DW, Kurland LT, Offord KP, Beard CM, (1986) Familial adult motor neuron disease: amyotrophic lateral sclerosis. Neurology 36: 511-517.

Ruzza P, Rosato A, Rossi CR, Floreani M, Quintieri L (2009) Glutathione transferases as targets for cancer therapy. Anti-Cancer Agents in Medical Chemistry 9: 763-777.

Samso M, Radermacher M, Frank K, Koonce MP (1988) Structural characterization of a dynein motor domain. J Mol Biol 27: 927-937.

Sawicki J, Kuźma M, Barańczyk-Kuźma A, (2000) The effect of serotonin, its precursors and metabolites on brain glutathione-S-transferase. Neurochem Res 265: 469-472.

Shung W, Jiu WH, Zhao XH, Sun JQ, Bi JZ, Chi ZF (2008) Espression of glutathione S-transferase alpha, mu, and pi in brains of medically intractable epileptic patients. BMC Neurosc 9: 67-71.
Rowland LP, ed (1995) Hereditary and acquired motor neuron diseases. In: Merritt's Textbook of Neurology, Williams \& Wilkins, Baltimore, pp. 742-749.

Teuchert M, Fischer D, Schwalenstoecker B, Habisch, HJ, Bockers TM, Rudolph AC, (2006) A dynein mutation attenuates motor neuron degeneration in SOD1G93A mice. Exper Neurology 198: 271-274.

Terro F, Lesort M, Viader F, Ludolph A, Hugon J (1996) Antioxidant drugs block in vitro the neurotoxicity of CSF from patients with amyotrophic lateral sclerosis. Neuroreport 7: 1970-1972.

Tew KD (1994) Glutathione-associated enzymes in anticancer drug resistance. Cancer Res 54: 4313-4320.

Tew KD, Ronai Z, (1999) GST function in drug and stress response. Drug Res Updates 2: 143-147.

Tuy PH, Raju P, Robinson KA, Gurney ME, Trojanowski JQ, Lee VM (1996) Transgenic mice carrying a human mutant superoxide dismutase transgene develop neuronal cytoskeletal pathology resembling human amyotrophic lateral sclerosis lesions. Proc Nat Acad Sci USA 93: 3155-3160.

Usarek E, Gajewska B, Kaźmieczak B, Kuźma M, Dziewulska D, Barańczyk-Kuźma A (2005) A study of glutathione-S transferase pi expression in central nervous system of subject with amyotrophic lateral sclerosis using RNA extraction from formalin-fixed, paraffinembedded material. Neurochem Res 30: 1003-1007. 